\title{
The Effect of Boldness Program on Increasing the Level of Non-verbal Communication Skills of Autism Children
}

\author{
Akram Hafezi ${ }^{1}$, Maryam Sadat Fakhimpoor ${ }^{2,}{ }^{*}$, Azam Kedri ${ }^{3}$ \\ ${ }^{1}$ Curriculum Planning, Farhangian University, Tehran, Iran \\ ${ }^{2}$ Imam Javad Institute of Higher Education, Yazd, Iran \\ ${ }^{3}$ General Psychology, Faculty of Psychology, Payame Noor University, Shiraz, Iran
}

Email address:

m.fakhimpoor@gmail.com (M. S. Fakhimpoor)

${ }^{*}$ Corresponding author

\section{To cite this article:}

Akram Hafezi, Maryam Sadat Fakhimpoor, Azam Kedri. The Effect of Boldness Program on Increasing the Level of Non-verbal Communication Skills of Autism Children. International Journal of Education, Culture and Society. Vol. 6, No. 4, 2021, pp. $129-137$. doi: $10.11648 /$ j.ijecs.20210604.15

Received: June 11, 2021; Accepted: July 12, 2021; Published: July 28, 2021

\begin{abstract}
The aim of this study was to investigate the effectiveness of group assertiveness program on increasing the level of social skills of autism spectrum disorders children. Using the social skills questionnaire (Ahmadi et al. 1997), children whose communication skills score was less than 100 were identified. These individuals were selected as a sample and then randomly divided into experimental and control groups. The statistical sample of this study included 30 autism children who were randomly selected. The experimental and control groups were divided into two groups of 15 people. Then, the group training program was taught to the experimental group in 10 sessions. After this training, social skills tests were performed on both groups. Finally, Data were Analise. According to the results, The experimental group is children who were trained in a daring program; They performed better than the control group in the non-verbal communication skills test. That is, the group assertiveness program was effective in enhancing the nonverbal communication skills of children on the autism spectrum. Generally. General education, formal adult education, tutoring and various educational materials that should be provided to them by various centers. Some forms of exercise-behavior are often used in the training of courage and ascension.
\end{abstract}

Keywords: Boldness Program, Non-verbal Communication Skills, Exceptional Children

\section{Introduction}

Due to the complexity of living conditions, the issue of "social interaction" has received a lot of attention in recent years. It may be accompanied by a real behavioral defect. The person may not know how to express themselves properly. In this case, the tone of voice, body movements, eye contact and other variables related to the way the person responds through modeling, practice Periodic Behavior and Feedback Needs Retraining [1]. Low-courageous individuals have a fear of confronting others. When such behavior disrupts other functions. It will be useful to use the technique of therapy to express and express emotions. Learning to express and express emotions is the same as learning [2]. In theories of behavior, daring to express oneself is considered as something. Which reflects a skill defect, specific or inhibitory, behaviors that are likely to be incorrect from learning social experiences. It should be said that daring, assertiveness, expression of feelings, attitudes teach a person to easily express his ideas and beliefs in different situations. Courage in teaching the appropriate social behaviors to express oneself, express feelings, attitudes teaches a person to easily express himself in various situations and participate in social relationships, and this increases his self-confidence and self-confidence. Such a person knows and believes in his / her abilities and limitations and achieves success in education and social communication with positive selfconfidence and self-concept [3]. A person who dares to communicate closely with others, to distance himself from the abuses of others, and to express a wide range of positive and negative needs and thoughts, without feeling guilty or anxious. Or harm the rights of others [4]. Boldness skills include taking one's rights and expressing one's thoughts, 
feelings, and beliefs appropriately, directly, and honestly, so that the rights of others are not violated. The way one communicates with others is an important factor in social interaction. Poor communication can lead to unhealthy relationships and increase stress. One of the most important factors in interpersonal communication is the correct use of assertiveness skills. People with poor assertiveness skills have problems both for themselves and for others [3]. Courage is one of the components of social relations and it is necessary to teach it in childhood that parents and teachers at any age should teach them these components. Courage means that one can defend one's rights and beliefs without aggression. In the skill of courage, the goal is to change oneself, not to change others so that one can express one's wants, needs, thoughts and feelings, and avoid social harm. Acquire social skills, how to communicate with other people, and social adjustment, including the desired skill set. Studies show that there is a relationship between students' audacity and their social adjustment [5]. Boldness is a skill that is regularly emphasized in teaching social and communication skills. This skill is in the chapters provided by the World Health Organization and its training is necessary for all people. Courage is one of the communication skills (interpersonal skills). Courage means being able to act in a calm and positive way to realize your rights and the rights of others, without being aggressive or passively accepting "wrong". People who have the courage can speak out without upsetting others or themselves. Although all people sometimes act aggressively or passively, such a response is a result of lack of self-confidence and therefore an inappropriate way to interact with others. This article examines the rights and responsibilities of assertive behavior and aims to show you the benefits of assertiveness. Courage is not in conflict with laws, norms and ethics. Courage means standing up and talking about your personal rights; being able to express your thoughts, feelings and beliefs in a direct, appropriate and honest way. There are different synonyms for courage. All of these synonyms are used in articles: assertiveness, assertiveness, assertive behavior, selfexpression is some of these synonyms. It is also important to note that: Respect the feelings and beliefs of others. Those who act boldly always respect their own thoughts, feelings, and beliefs, as well as others. Boldness means being able to express our feelings, desires, desires, and aspirations appropriately. And a very personal and interpersonal skill is very important. In all your interactions with others, whether at home or at work with employees, customers or coworkers, daring helps you to express yourself clearly, openly and sensibly, without Take away the rights of your learners. Courage enables people to act in their own interests, to claim their rights without undue anxiety, to express their honest feelings easily, and their personal rights without denying the rights of others [6]. A student with autism who has the ability to express himself / herself has a better self-image and abilities and respects himself / herself. Learning includes methods of teaching skills through which social behaviors (verbal and non-verbal) are taught. And is practiced and coordinated with the individual's behaviors. Children with ASD by the age of 24 to 30 months often appear relatively normal in their development. It is at this age that parents notice a delay in their child's language, speech, play, or social interactions. Of course, a disorder in any of the above cases will not in itself be a sign of a definitive diagnosis of ASD. Is. Coax and Goldstone [4] The frustration or sadness that these children feel causes them to avoid taking the lead in socializing or to avoid it when another child tries to approach them. Such children are less popular and in their relationships. Contrary to popular belief, many children with ASD may make eye contact, react lovingly, smile and laugh, and show other types of appropriate emotions to varying degrees. Just like other children. Respond positively and negatively to their surroundings. ASD may affect their response rate in a way that makes it harder for the body and mind to control the external stimulus. Sometimes there is a problem with peripheral vision (not vision) and the muscular structure of the eyes allows eye contact. Some people with ASD use an environmental perspective instead of looking directly at others. Sometimes people with ASD withdraw from family and friends because the thought of being touched by someone or even getting too close. Physicality is unbearable for them. Anxiety, fear and confusion can lead to an inability to understand the environment in a normal routine. Weakness in social relationships is one of the most important problems for these children. Common dependence on parents and others. These children avoid looking into the eyes of others (even their parents). They do not even use gestures, gestures and facial expressions to communicate with others, they may not really feel anxious or separated. It is evident in playing with peers and finding a friend. Occupational therapy plays a very effective role in treating communication problems in these children. One of the most important goals in the education of children with autism is social adjustment, establishing useful and effective relationships with others and accepting social responsibilities in skills that are mostly in the field of self-help. Play can strengthen the process of adjustment to society in children. These games should be planned and performed directly or indirectly on emotional or physical issues and based on the type of disorder present. There is a lot of research on the use of daring training as a treatment method. It is done, some of which are referred to:

Mazloumian et al. [5] concluded that high reduction of boldness has an adverse effect on academic performance, job and individual efficiency, and considering the effectiveness of the assertiveness training method in increasing boldness, it is suggested that boldness training as Used a useful and effective method to increase students' audacity.

The results of Nazar. A. et al. [7] show that there is no significant difference between the social skills of the experimental group in pre-test and post-test and the control group in pre-test and post-test. There is no significant difference. The comparison of the mean scores of subjects in the two groups shows The social skills of the subjects in the experimental group in the post-test group are more than the 
control group. In general, based on the findings, it can be said that courage training through group counseling is effective in improving social skills and academic education of students.

The results of the research of Bigdelou et al. [4] showed that teaching communication skills to students' boldness is also significant.

The results obtained in the study of Shabibasl et al. [8] showed that training and exercise increased social anxiety in the tested group and the follow-up results showed that differences in the scores of following social anxiety to continue the effectiveness of training. is daring (group membership).

The results of analysis of covariance of Mardani et al. [2] in the training method showed more self-esteem and social skills in the experimental group than the control group.

According to the results obtained in the study of Navidfar et al. [9], the experimental group performed better than the control group in the social skills test. That is, the group assertiveness program was effective in increasing the social skills and nonverbal social relationships of students with hearing impairment.

Rezapour Mirsaleh, Yaser, Aboutorabi Kashani, Parisa, Ebrahimi Ghavam, Soghari. [18] In a pilot study, the positive effect of courage training on academic achievement and social skills of middle school and high school girls in the region has been reported.

Guttman, Gonz, and Schuler (2008) used a multicultural behavioral program with isolated children, using selfsuspended speech patterns, preparing and teaching social skills, and observed that after treatment, their relationship with His peers rose.

Arindel, Sanderman, Hagman, and Pickersgill [17] in several studies examined assertiveness in clinical and nonclinical specimens. In eight studies, they showed that between daring behavior with social fears (social anxiety, hadron aggression) such as criticism. There is a link between extreme self-loathing and delusional guilt (shyness, lack of self-confidence, and low self-esteem.) They also found that there was a negative relationship between reckless behavior and independent behaviors, social self-sufficiency, selfconfidence, and high self-esteem.

From what has been said, childhood deficiencies in relationships and non-verba are transferred to adulthood. Awareness of the need for social skills training is often gained by examining the relationship between social behavior (assertiveness and self-confidence) and academic achievement. People with assertiveness are assertive and provide immediate and spontaneous answers to questions. They use non-verbal interaction, ie eye contact and facial expressions, to express their feelings, thoughts and needs, and that is why they control problems and deal with challenges in social situations [16]. non-verba are one of the basic needs of all. People, especially people with autism, have difficulty acquiring certain social skills due to their limitations. The need to establish healthy and useful relationships with others, to refrain from abuse, to make decisions, to choose freely, to express thoughts about oneself without guilt, and Participation in social interactions that are their basic need [15] Now people who do not have proper communication and social skills will have many problems. People with autism are a group of people who need to acquire social skills from Through family and school Helping them. Bravery is one of the skills needed to communicate these people usefully with others (Khorramabadi, 1998). Every person with ASD is unique and, like everyone else, has a unique personality and a mix of characteristics. There are many differences between people with ASD. Some people with mild ASD may have slight delays in speech and language, but may have more difficulty socializing and communicating with others. Start a conversation to communicate and keep talking to others. They do not have the ability to continue, but it continues despite the efforts of others to cut it off. People with ASD have information, both external and internal, in unique and self-controlled ways and react. Given what has been said, people with disabilities are at the same level as other groups in terms of basic life and social skills. Many children and adolescents with autism often fail academically due to lack of courage and assertiveness. Learned helplessness, isolation, isolation, and depression. In other words, children and adolescents with low and daring autism gradually lose their sense of self-worth as a result of which their motivation to do things decreases and therefore suffers. Consecutive failures occur and these failures create in them the belief that they will never be successful people at the social level, so they reduce their efforts and practically do not engage in new experiences. The development of these children and adolescents with bitter and unsuccessful experiences, their daring state continues and increases over time [10]. Children with autism are more prone to mental disorders and compromise There are psychological deficiencies. During learning skills, a child with autism has serious problems in establishing a correct and effective relationship with the environment. Able to receive and understand It is not a complete description of others and educators and cannot express their needs. At this stage, the child seems less intelligent than he is [11]. Social and personality development of individuals in general depends on How they relate to others Language is the most important means of communication among ordinary people. A person who has the courage can communicate closely with others, protect himself from the abuse of others, can make decisions and choices freely, and Can express a wide range of positive and negative needs and thoughts to feel guilty and anxious or harm the rights of others [10] A person with autism who has a high level of courage and social skills. Social interactions with others, especially ordinary people, are successful, but the lack of self-expression and lack of adequate social skills is a major barrier for people with autism in social issues and social communication, so improving their daring and social skills is essential. It seems [3]. Because these children have difficulty expressing ideas and beliefs and cannot easily express their feelings and emotions, so they have difficulty in establishing a correct and logical relationship with those around them and gradually 
move away from society and social relations. Pay. Courage teaches the appropriate social behaviors to express oneself, express emotions, attitudes so that one can easily express oneself in various situations and participate in social relations, and this is self-belief and It boosts self-confidence in him. Such a person recognizes and believes in his abilities and limitations and achieves success in his education and social communication with positive self-belief and selfconcept. Assertiveness training is also a method of intervention designed to enhance interpersonal skills. In fact, in the present study, we extend the training of assertiveness program on the assumption that weakness in social skills is associated with inadequate interpersonal function. In this study, considering the characteristics of daring people with autism and the positive effects that daring can have on such people, The researcher will seek to evaluate the effects of the group assertiveness program on increasing the level of nonverbal communication skills of exceptional children.

1) Implementing a group boldness program is effective on the smile of autistic children.

2) Implementing a group boldness program affects the level of respect for children with autism.

3) Implementing a group boldness program is effective in the rate of joining activities in children with autism.

4) Implementing a group boldness program is effective in inviting others by children with autism.

5) Implementing a group boldness program is effective on the level of communication skills of autistic students.

\section{Objectives of Ten Sessions}

The group daring program as taught will be taught in 10 sessions, each session has specific goals that will be based on the objectives of each session, training and activities, and at the end of each session, assignments to strengthen the knowledge taught. Students will be assigned. It should be noted that the full description of all activities related to this training program is included in the appendix of this research, and we only mention the objectives of each session here.

\subsection{Objectives of the First Session}

1) Preparing or guiding people.

2) Statement of group regulations and objectives of its formation.

3) Explain the logic of treatment through clear examples.

4) Introducing people.

5) Positive feedback from people on how to introduce with regard to (eye contact, facial expressions, body posture and tone of voice).

\subsection{Objectives of the Second Session}

1) Preparing group members for nonverbal behaviors that affect their first perceptions.

2) Identify the behaviors that participants are currently using.

3) Pay attention to the nonverbal behaviors that participants have chosen to change during the group session.

4) Giving feedback on the specific behaviors of group members.

5) Explain that positive interactions require courage.

\subsection{Objectives of the Third Session}

1) People see themselves as effective and capable of changing themselves and feel more capable.

2) Helping people to correct misunderstandings about bold, aggressive, and daring behavior.

3) Expressing one's emotional reactions to different situations.

4) Guiding people in recognizing and accepting their human rights.

\subsection{Objectives of the Fourth Session}

1) Preparing members so that they can ask others for work or help.

2) Rejecting the unreasonable and unfair demands of others.

3) Instead of being angry with criticism, deal with it correctly.

4) Learn to express themselves better to others by expressing emotions.

\subsection{Objectives of the Fifth Session}

1) People in the group learn the differences between thinking, feeling and behaving.

2) Learn some irrational underlying beliefs.

\subsection{Objectives of the Sixth Session}

1) People pay attention to the value of human beings.

2) Members are able to express their abilities without feeling uncomfortable.

3) Understand negative and positive expressions in their expressions.

\subsection{Objectives of the Seventh Session}

1) Paying attention to individual differences and accepting being different from others.

2) Familiarity with some differences between people.

3) Coping with existing differences.

\subsection{Objectives of the Eighth Session}

1) People pay attention to their positive points and express them.

2) Finding skills in expressing oneself in public.

3) Find the skill to break your own silence when you need to talk.

\subsection{Objectives of the Ninth Session}

1) People without guilt say no to the unjust demands of others.

2) People should get acquainted with the techniques that 
the Egyptian people should face so that others do not trample on their rights.

3) People can express their opinions, especially different opinions from important people.

4) People feel comfortable expressing their thoughts and feelings by considering their own rights and those of others.

\subsection{The Purpose of the Tenth Session}

Evaluation of meeting results.

\section{Research Method}

In order to answer the research questions, the eclectic method has been used here, ie quantitatively and qualitatively. In the quantitative method, the quasiexperimental method and in the qualitative method, the case study have been used. The research plan is semiexperimental as a preliminary and final test with The control group and the use of random sampling. In this study, the experimental and control group will include male and female students with autism who have low levels of social skills. The independent variable, ie group assertiveness program, during 10 sessions on The experimental group will be applied and the control group will be protected from the influence of such a factor. The statistical population is all students with autism in Tehran. A total of 30 students were randomly selected by available sampling method. In this study, in order to collect information from Ahmadi and Nourani [14] Social Skills Questionnaire and Daring Training Program. Group used. This questionnaire has 40 questions, which is answered by the 5-point Likert method. This tool has acceptable reliability features, while comparing some scores with a more uniform distribution than its predecessors. This test has a good validity as this test explains between 30 to $35 \%$ of the variance between individuals based on the registration of relationships and social interactions related to verbal and non-verbal social skills. The validity of children's social skills test is usually more than $80 \%$ alpha. Has been seen.

After selecting the sample from the statistical population, the samples were randomly divided into two groups of experimental and control. And control, under the same conditions, Ahmadi and Noorani social skills test was performed on both groups. This stage is considered as pretest. After performing the pre-test stage, the experimental group was trained in daring skills in 10 sessions, but the control group They did not receive these trainings and skills. Then, immediately after the end of the daring training sessions, both experimental and control groups were assessed again under the same conditions through social skills questionnaires. The results were analyzed. In the present study, using SPSS software in two descriptive and inferential levels, the obtained data have been analyzed. At the descriptive level, the following statistical indicators have been used while classifying the data: frequency-frequency indices, frequency percentage Density percentage (central tendency indices and dispersion indices (variance), standard deviation, standard error, mean) at the level of inferential statistics were used in proportion to the statistical analysis of multivariate analysis of covariance. We have tried to attribute the observed changes in the post-test to the experimental variable. In fact, the main reason for choosing this method is that this statistical method by comparing the pre-test and post-test results allows us to We can compare pre-test and post-test results And conclude whether this educational method has been effective in improving the non-verbal communication skills of exceptional children.

\section{Findings}

The purpose of this study is to investigate the effect of boldness program on increasing the level of non-verbal communication skills of exceptional children through action research. The findings of the study are as follows: The present study was performed on a sample size of 30 primary school students with autism. Subjects were randomly divided into experimental $(n=15)$ and control $(n=15)$ groups.

Hypothesis 1: Implementing a group assertiveness program is effective on the smile rate of students with autism.

To test this sub-hypothesis, we first examine the descriptive findings of the smile variable in the following table:

Table 1. Descriptive indicators of the control and experimental groups in the smiling variable.

\begin{tabular}{lllll}
\hline & group & number & average & Standard deviation \\
\hline \multirow{2}{*}{ pre-test } & the experiment & 15 & $11 / 46$ & $1 / 50$ \\
& Witness & 15 & $11 / 33$ & $1 / 54$ \\
\multirow{2}{*}{ Post-test } & the experiment & 15 & $19 / 13$ & $0 / 75$ \\
& Witness & 15 & $11 / 33$ & $1 / 54$ \\
\hline
\end{tabular}

According to the information in the table above, the number of people in the experimental and control groups is equal to 15 people. The mean scores of the pre-test smile were $11 / 46$ in the experimental group 11/54.11 and the standard deviation of the experimental group was 11/5 times.
Also, the mean post-test scores of the experimental group in smiling were 19/33 and the mean scores of the control group were $11 / 33$ and the standard deviation of the scores of the control group was $1 / 54$. The standard deviation of the scores of the experimental group was 74.0. 
Table 2. Results of post-test analysis of covariance based on smile pre-test.

\begin{tabular}{llllll}
\hline Source & Total & grade & average & F & Significance \\
\hline Model & $467 / 01$ & 2 & $233 / 50$ & $207 / 69$ & $0 / 001$ \\
Interaction & $55 / 41$ & 1 & $55 / 41$ & $49 / 28$ & $0 / 001$ \\
Before & $10 / 71$ & 1 & $10 / 71$ & $9 / 52$ & $0 / 005$ \\
group & $449 / 07$ & 1 & $449 / 07$ & $399 / 43$ & $0 / 001$ \\
Error & $30 / 35$ & 27 & $1 / 12$ & & \\
Total & $497 / 367$ & 29 & & & \\
\hline
\end{tabular}

Based on the information in the table above, the sum of the squares of variance observed in the model was equal to $467 / 01$ is due to grouping and finally the value of $30 / 35$ is due to error. The sum of the set of hardships due to pre-test and grouping is equal to 7.459 which together with the sum of error repetitions and interaction explains the total repetition of the model. Significant effects in this model are the pre-test effect at the significance level of 0.01 and the grouping effect at the significance level of 0.001 .

Table 3. A study of the differences between the means of the groups in terms of smiling skills.

\begin{tabular}{lllllll}
\hline group & group & average & Standard deviation & grade & T & Significance \\
\hline experiment & experiment & $19 / 13$ & $0 / 74$ & 28 & $17 / 63$ \\
Witness & Witness & $11 / 33$ & $1 / 54$ & & \\
\hline
\end{tabular}

According to the information in the table above, the value of $t$ for the post-test scores of the smiling variable in the two experimental and control groups with a degree of freedom of 28 was $17 / 63$ which was significant at the level of 0.01 ..
Hypothesis 2: The implementation of a group assertiveness program is effective on the level of respect for students with autism.

Table 4. Descriptive indicators of the control and experimental groups in the respect variable.

\begin{tabular}{lllll}
\hline & group & number & average & Standard deviation \\
\hline \multirow{2}{*}{ pre-test } & the experiment & 15 & $12 / 26$ & $1 / 50$ \\
& Witness & 15 & $12 / 20$ & $1 / 54$ \\
\multirow{2}{*}{ Post-test } & the experiment & 15 & $20 / 40$ & $0 / 82$ \\
& Witness & 15 & $12 / 20$ & $1 / 26$ \\
\hline
\end{tabular}

According to the information in the table above, the number of people in the experimental and control groups was equal to 15 people. The mean scores of the respect test in the experimental group was $12 / 26$ and in the control group was $12 / 20$. The standard deviation of the group scores The test was equal to 5.1 and the standard deviation of the control group scores was 1/54 Also, the mean score of the post-test group in respect was 40.20 and the mean score of the control group was equal to $12 / 20$. The standard deviation of the group scores was The test was equal to 0.82 and the standard deviation of the scores of the control group was $1 / 26$.

Table 5. Results of post-test analysis of covariance based on pre-test respect.

\begin{tabular}{lllll}
\hline Source & Total & grade & average & F \\
\hline Model & $616 / 79$ & 2 & $258 / 39$ & $713 / 13$ \\
Interaction & $29 / 25$ & 1 & $29 / 25$ & $11 / 11$ \\
Before & $12 / 49$ & 1 & $61 / 19$ & $12 / 49$ \\
group & $499 / 63$ & 1 & $199 / 17$ & $499 / 63$ \\
Error & $19 / 50$ & 27 & $1 / 311$ & $0 / 722$ \\
Total & $536 / 30$ & 29 & & $0 / 001$ \\
\hline
\end{tabular}

Based on the information in the table above, the sum of the squares of variance observed in the model was 536/30 is due to grouping and finally the value of $19 / 50$ is due to error. The sum of the totalities due to pre-test and grouping is equal to $512 / 1$ which together with the sum of errors and interaction explains the total totality of the model. Significant effects in this model are the effect Pre-test at the significance level of 0.001 and the effect of grouping at the significance level of 0.001 and the effect of interaction at the significance level of 0.001 .

Table 6. Examines the differences between the means of the groups in terms of respect skills.

\begin{tabular}{llllll}
\hline group & group & average & Standard deviation & grade & T \\
\hline experiment & experiment & $20 / 40$ & $0 / 82$ & 28 & $21 / 006$ \\
Witness & Witness & $12 / 20$ & $1 / 26$ & & \\
\hline
\end{tabular}


Based on the information in the table above, the value of $t$ for the post-test scores of the variable of respect in the experimental and control groups with a degree of freedom of 28 was equal to 0.006 , which was significant at the significance level of 0.001 . Has been respected.

Hypothesis 3: The implementation of group assertiveness program is effective on the rate of joining activities in autistic students.

Table 7. Descriptive indicators of the control and experimental group in the variable of joining the activities.

\begin{tabular}{lllll}
\hline & group & number & average & Standard deviation \\
\hline \multirow{2}{*}{ pre-test } & the experiment & 15 & $10 / 40$ & $0 / 91$ \\
& Witness & 15 & $10 / 06$ & $0 / 79$ \\
\multirow{2}{*}{ Post-test } & the experiment & 15 & $16 / 40$ & $0 / 73$ \\
& Witness & 15 & $10 / 13$ & $0 / 83$ \\
\hline
\end{tabular}

Based on the information in the table above, the number of people in the experimental and control groups was equal to 15 people. The mean pre-test scores for joining the activities in the experimental group was 10/40 and in the control group was 10/06 The standard deviation of the control group scores was 0.83 . Also, the mean post-test scores of the experimental group in joining the activities were 40.16 and the average score of the control group was 10/13 The standard deviation of the experimental group scores was 0.73 and The standard deviation of the control group scores was 0.83 .

Table 8. Results of post-test analysis of covariance based on pre-test joining activities.

\begin{tabular}{llllll}
\hline Source & Total & grade & average & F & Significance \\
\hline Model & $300 / 93$ & 2 & $150 / 46$ & $371 / 70$ & $0 / 001$ \\
Interaction & $11 / 11$ & 1 & $11 / 11$ & $27 / 44$ & $0 / 001$ \\
Before & $6 / 40$ & 1 & $6 / 40$ & $0 / 8 / 81$ & $658 / 28$ \\
group & $266 / 48$ & 1 & $266 / 48$ & $0 / 001$ \\
Error & $10 / 93$ & 27 & $0 / 405$ & \\
Total & $311 / 00$ & 29 & & \\
\hline
\end{tabular}

Based on the information in the table above, the sum of squares of variance observed in the model was 311. In separating this sum of squares into its components, we see that 11.11 due to the interaction of the pretest with the grouping, 6/40 due to the pretest, 266/48 due to Grouping and finally the value of 10/93 is due to error. The sum of the set of objects resulting from the pre-test and grouping is equal to $227 / 8$ which together with the set of errors and interaction explains the total set of constraints of the model. Significant effects in this model are: The effect of pre-test at a significance level of 0.01 and the effect of grouping at a significance level of 0.001 and the effect of interaction at a significant level of 0.001 .

Table 9. A study of the differences between the means of the groups according to the skills of joining the activities.

\begin{tabular}{llllll}
\hline group & number & average & Standard deviation & grade & T \\
\hline experiment & 15 & $16 / 40$ & $0 / 73$ & 28 & $21 / 812$ \\
Witness & 15 & $10 / 13$ & $0 / 83$ & & $0 / 001$ \\
\hline
\end{tabular}

Based on the information in the table above, the value of $\mathrm{t}$ for the post-test scores of the variable of joining activities in the experimental and control groups with a degree of freedom of 28 was $21 / 812$, which was significant at the significant level of 0.001 . And has had a significant impact on joining activities.

Hypothesis 4: The implementation of group education program is effective on the extent to which others are invited by children with autism.

Table 10. Descriptive indicators of the control and experimental group in the variable of inviting others.

\begin{tabular}{lllll}
\hline & group & Standard deviation & average & number \\
\hline pre-test & the experiment & $0 / 70$ & $7 / 06$ & \\
& Witness & $0 / 65$ & $7 / 00$ & 15 \\
Post-test & the experiment & $0 / 45$ & $15 / 26$ & 15 \\
& Witness & $0 / 65$ & $7 / 00$ & 15 \\
\hline
\end{tabular}

According to the information in the table above, the number of people in the experimental and control groups was equal to 15 people. The standard deviation of the experimental group scores was 0.7 and the standard deviation of the control group scores was 0.65 . Also, the mean post-test scores of the experimental group in inviting others was $15 / 26$ and the average score of the control group was 0.7 . The standard deviation of the experimental group scores was 0.45 and the standard deviation of the control group scores was 0.65 . 
Table 11. Results of post-test covariance analysis based on pre-test inviting other people.

\begin{tabular}{llllll}
\hline Significance & Total & grade & average & Significance & F \\
\hline Model & $514 / 26$ & 2 & $257 / 13$ & $0 / 001$ & $964 / 11$ \\
Interaction & $18 / 98$ & 1 & $18 / 98$ & $0 / 001$ & $71 / 19$ \\
Before & $1 / 73$ & 1 & $1 / 73$ & $0 / 001$ & $6 / 49$ \\
group & $508 / 20$ & 1 & $508 / 20$ & $0 / 001$ & $190 / 48$ \\
Error & $7 / 20$ & 27 & $0 / 267$ & & \\
Total & $521 / 46$ & 29 & & & \\
\hline
\end{tabular}

Based on the information in the table above, the sum of the squares of variance observed in the model was $26 / 14$ is due to grouping and finally $7 / 20$ is due to error. The sum of the set of rigors resulting from the pretest and grouping is equal to 510 , which together with the sum of the error recalls and the interaction explains the total sum of the model recalls.

Significant effects in this model are pre-test effect at a significance level of 0.001 , grouping effect at a significant level of 0.001 and interaction effect at a significant level of 0 . 001 .

Table 12. Study of the difference between the means of the groups according to the skill of inviting other people.

\begin{tabular}{|c|c|c|c|c|c|c|}
\hline group & number & average & Standard deviation & grade & $\mathbf{T}$ & Significance \\
\hline experiment & 15 & $15 / 26$ & $0 / 45$ & \multirow{2}{*}{28} & \multirow{2}{*}{$40 / 081$} & \multirow{2}{*}{$0 / 001$} \\
\hline Witness & 15 & $7 / 00$ & $0 / 65$ & & & \\
\hline
\end{tabular}

Based on the information in the table above, the value of $t$ for the post-test scores of the variable of inviting other people in the experimental and control groups with a degree of freedom of 28 was $40 / 081$, which was significant at the significance level of 0.001 . This shows that daring skills training has a positive and significant effect on inviting other people.

\section{Discussion}

In this study, the effect of boldness program on increasing the level of nonverbal communication skills of exceptional children was investigated. The results showed that social skills acquisition is a process in which criteria, skills, motivations, Attitudes and social behaviors are formed. Family, peers and teachers are involved in its upbringing, and the educator can create opportunities for children to improve their social skills by making changes in educational situations. One of the most basic issues of special education. It is an attempt to eliminate social separation and social adaptation of people with autism. This type of separation is closely related to cognitive abilities; is the lack of basic knowledge keeps him away from education. In reducing and solving this group of people, various measures should be taken. General education, formal adult education, self-study and various educational materials that should be provided to them by different centers. Non-immigrants indicate a behavioral defect in that the person is presumed to lack some behavioral skills and Social is clear. In fact, in the training of courage and assertiveness, often of some form Behavioral practice is used [12].

Exceptional children, especially children with autism, have many needs, including the need for social and communication skills due to their limitations as well as the dysfunctional education system and lack of parental awareness. These needs are often not met. There are many ways to help children with special needs to develop their social skills. Group learning is one of the most effective ways to teach how to communicate with others [13].

\section{Conclusion}

Research has shown that implementing a learning program It can improve the Communication skills of autistic children. From the summary of research records that have been mentioned, it can be concluded that many problems of children, especially children with autism, in the field of social skills as well as in establishing social communication in the form of Verbal and non-verbal are the main problems of these children in the field of expression and expression in such a way that they can show their abilities and capabilities. Research information shows that courage training has a positive and significant effect on skills. At the end of the study, the following behavioral changes were observed in the children in the experimental group: The child had less difficulty speaking and was able to express himself, it was easier for him to say something in general, than before. He did not disobey his teacher, the child did not interrupt others, he was not shy and Do not shy away from group work and love to take the lead in making friends with others. Many factors may jeopardize the internal and external credibility of the research. Therefore, researchers are doing their best to remove these barriers and increase the credibility of their research.

In the present study, we also faced limitations in each area, including: The effect of pre-test on learners' readiness for post-test; Synchronous effect of some other variables that may have occurred during the research. The effects of measuring instruments and their validity and reliability may affect the results. According to the research findings, it is suggested that: Suggest to researchers to use observation and case study methods in data collection and to use qualitative research methods to examine the effect of these variables on the whole personality of children as a whole and not on one or two variables alone. 


\section{References}

[1] Goldfried, M. R., \& Davison, G. C. (1994). Clinical behavior therapy, Exp. John Wiley \& Sons.

[2] Mardani, Azita and Azadi, Shahdokht, 2017, Evaluation of the effectiveness of group assertiveness program on increasing social skills of Gachsaran first high school girls, 3rd International Conference on Psychology, Sociology of Educational Sciences and Social Studies, Shiraz.

[3] Mohammadian, Abdullah, Livarjani, Sholeh, Azmoudeh, Masoumeh. (2018). Comparison of social anxiety, selfefficacy and stubbornness دوم psychological of high school students with different levels of audacity. Women and Family Studies, 11 (40), 105-122.

[4] Bigdelou, T,. Zanganeh, S. Khorramabadi, Y. (2019). The effect of communication skills training on the courage of high school male students in Bazinehroud region, 4th National Conference on Psychology, Research and Educational Sciences, Shirvan.

[5] Mazloumian, S and Ghaheri, M. (2020). Students' Courage and Social Adjustment, 7th National Conference on New Studies and Research in the Field of Educational Sciences, Psychology and Counseling, Iran, Tehran.

[6] Ragabi, F. (2020). Courage and its role in life, 3rd International Conference on Psychology, Educational Sciences, Social Sciences and Humanities.

[7] Nazar A, Shahnaz and Navabi N, S and Ahghar, G. (2020). Study and comparison of the effect of assertiveness training through group counseling on increasing social skills of students of Shahid Beheshti University of Medical Sciences, 7th International Conference on Psychology, Counseling and Educational Sciences.

[8] Shabib Asl, N and Homayi, R. (2019). The effect of courage training on social anxiety in preschool children in Ahvaz, 4th International Conference on New Research in Educational Sciences and Psychology and Social Studies in Iran, Tehran.
[9] Novidfar B, Sharifi Daramadi P, Mahboobi K. (2012). Effect of training Program Assertiveness training Group to increase social Skills School Students with hearing Impairment City Boukan. J Except Educ. 4 (112): 7-17.

[10] Pasha, Reza. (2013). The effect of assertiveness training on students' self-esteem, social anxiety and assertiveness. Educational Studies, 3 (4), 99-114.

[11] Malekan Rahimeh, Pousheneh Kambiz, Esteki Mahnaz. The effect of comprehensive interaction training on reducing challenging behaviors and increasing social skills in children with autism spectrum disorder. Exceptional Children Quarterly. 2020; 20 (2): 101-114.

[12] Mahmoodi, Mohammad (2011). Evaluation of the effectiveness of short-term treatment focused on metacognition on the symptoms of social phobia disorder, a single subject review. Journal of Mental Health Principles, 12 (47), 41-630. doi: 10.22038 / jfmh.2010.1045.

[13] Atler, R. Hardman, M, 2003, Your perfect right; a guide for assertive Living, Impact. sun luis opispo. California.

[14] Ahmadi. Sayed Ahmad, Nourani. Saghar, (2001), The effect of pantomime plays on the modeling of social skills of preschool children, Islamic Azad University, Khorasgan Branch of Isfahan, No. 7.

[15] You came honorably. Parviz, 2002. The Psychology of Exceptional Children (Vol. 2). Publisher: Psychometrics.

[16] Brotherton, J. A., \& Abowd, G. D. (2004). Lessons learned from eClass: Assessing automated capture and access in the classroom. ACM Transactions on Computer-Human Interaction (TOCHI), 11 (2), 121-155.

[17] Rosenberg, I. D. (2004). Adults' attachment style, views of parents and reported childhood and current fearfulness. Adelphi University, The Institute of Advanced Psychological Studies.

[18] Rezapour Mirsaleh, Yaser, Aboutorabi Kashani, Parisa, Ebrahimi Ghavam, Soghari. (1391). The effect of assertiveness skills training in increasing the courage and selfesteem of low-courageous third to fifth grade elementary school girls in Tehran. Clinical Psychology and Personality, $10(2), 77-90$ 